\title{
Antimicrobial effects of Photodynamic Therapy to gram negative bacteria envelope revealed by Cryo-electron tomography
}

Aguinaldo S. Garcez, Mohammed Kaplan, Silvia C. Nunez, Grant J. Jensen

Aguinaldo S. Garcez, Mohammed Kaplan, Silvia C. Nunez, Grant J. Jensen, "Antimicrobial effects of Photodynamic Therapy to gram negative bacteria envelope revealed by Cryo-electron tomography," Proc. SPIE 11070, 17th International Photodynamic Association World Congress, 110708W (7 August 2019); doi: 10.1117/12.2525451

SPIE Event: 17th International Photodynamic Association World Congress, 2019, Cambridge, Massachusetts, United States 


\title{
Antimicrobial effects of Photodynamic Therapy to Gram negative bacteria envelope revealed by Cryo-electron tomography
}

\author{
Aguinaldo S Garcez¹, Mohammed Kaplan², Silvia C Nunez ${ }^{3}$, Grant J Jensen² \\ ${ }^{1}$ São Leopoldo Mandic Institute and Research Center; \\ ${ }^{2}$ California Institute of Technology - Caltech; \\ ${ }^{3}$ Universidade Brasil
}

Cryo-electron tomography (cryo-ET) is an emerging technology that enables thin samples, including small intact prokaryotic cells, to be imaged in three dimensions in a near-native 'frozenhydrated' state to a resolution sufficient to recognize very large macromolecular complexes in situ. This methodology has been fundamental to provide information about cellular ultrastructure. This study used cryo-ET to evaluate the photodynamic effect on the viability and envelope architecture of a Gram-negative bacteria. Bacterial suspension of $E$. coli minicells were submitted to photodynamic treatment with methylene blue solution $(100 \mu \mathrm{M})$ and a $100 \mathrm{~mW}$ low power diode laser emitting at $660 \mathrm{~nm}$ with 6 and 18J of energy. As a control group, a suspension of minicells were submitted to 462 $\mathrm{IU} / \mathrm{mL}$ penicillin $\mathrm{G}$ for $60 \mathrm{~min}$ at $30^{\circ} \mathrm{C}$, to compare the damage in cell wall structure. After treatment bacteria were immediately plunge-frozen across EM grids and standard cryo-ET tilt series were collected, 3D images reconstructions were calculated and recorded. The imagens showed detachment of the bacterial cell walls and mesosome-like structures. In addition, some sites showed interrupted stretches in both inner and outer membranes and cell wall degradation, indicating bacterial envelope damage. Cryo-electron tomography revealed that the effects of photodynamic therapy on Gram negative bacteria was based on damage to the outer membrane, cell wall and inner membrane and occurs in an energy-dependent manner.

Keywords: E. coli, low power laser, Methylene blue, PDT

17th International Photodynamic Association World Congress, edited by Tayyaba Hasan, Proc. of SPIE Vol. 11070, 110708W · @ 2019 SPIE · CCC code: 0277-786X/19/\$21 · doi: 10.1117/12.2525451 


\section{1 - Introduction}

The increase of bacteria resistance to antibiotics has appeared as one of the most critical clinical challenges of this century in health care, the urgent need for effective alternatives to antibiotics, especially against the called "ESKAPE" bacteria (E. faecium, S. aureus, K. pneumoniae, A. baumanii, P. aeruginosa and Enterobacter spp.) is urgent ${ }^{1}$. Studies on novelty approaches, such as nanoparticles compounds ${ }^{2}$, cold plasma plume ${ }^{3}$, dye therapy ${ }^{4}$ and the use of light, particularly photodynamic therapy ${ }^{5,6}$, against pathogens are emerging and gaining attention ${ }^{7,8}$.

Antimicrobial Photodynamic therapy (aPDT) consists in an association of a non-toxic dye (known as a photosensitizer) and low power visible light to produce reactive oxygen species that kills microorganisms and/or cancer cells ${ }^{9}$. aPDT has been used more often in cancer treatment and ophthalmology for age-related macular degeneration ${ }^{10}$. However, recently this therapy has been investigated as an alternative approach against resistant microorganisms, especially in dental ${ }^{11}$ and dermatological infection ${ }^{12}$, as an alternative to antibiotics ${ }^{13}$.

This photochemical antimicrobial strategy involves the combination of a photosensitizer(PS) and a low-power light source. The excited PS reacts with molecular oxygen to produce highly reactive oxygen species, which provoke injury and death of microorganisms and cancer cells ${ }^{14}$. Photosensitizers that possess a cationic charge, can rapidly bind to or infiltrate into bacterial membranes and, therefore, these PS exhibits a high degree of selectivity for killing microorganisms and have little toxicity toward host cells ${ }^{15}$. aPDT has an efficient killing effect upon different classes of microorganisms, such as Gram-positive, Gram-negative bacteria and yeasts ${ }^{7,16}$. Also, previous studies compared aPDT of multi-drug resistant bacteria with wild-type strains and found identical killing of methicillin-resistant Staphylococcus aureus (MRSA) and native ones ${ }^{17}$ or resistant $E$. coli and sensitive strains ${ }^{18}$.

Trying to understand the effects of aPDT on microorganisms, different methods have been used. Scanning electron microscopy (SEM) ${ }^{19}$ and Atomic force microscopy (AFM) have shown similar results after photodynamic therapy on bacterial or yeast cell morphology ${ }^{20}$. Garcez et al. using SEM images found changes in E. faecalis and P. aeruginosas morphology, they described probable membrane disruption, loss of cocci or bacilli shape, and the presence of grooves on the cell surface. Melo et al. using AFM analysis, observed a reduction in size of PDT treated S. mutans, a gram-positive bacterial species. The authors reported that $S$. aureus cell envelopes had a smoother surface texture after PDT and they believe that these changes are related to structural alteration, indicating that there might be cytoplasm or other cellular 
contents leaking out of the bacteria. Probably due to peroxidation of lipids and proteins in cell membranes causing a loss of membrane integrity and ion homeostasis, resulting in cell necrosis. Also, Baptista et al. using AFM, Transmition Electron microscopy and Fourier transform infrared spectroscopy (FT-IR) to evaluate the photodynamic effect in fungal cells, found that morphological analysis revealed wrinkled and shrunk fungal cell membrane, extracellular polymeric substance removal and cell membrane damage after aPDT. These authors reported surface nano-stiffness reduction, cellular adhesion force was reduced showing degradation of nucleic acids and proteins and degradation of polysaccharides and lipids.

Electron cryotomography (ECT) is an alternative technique for determining the structure of cell membranes, organelles or small cells. Samples preserved in a 'frozen-hydrated' state are imaged in a transmission electron microscope (TEM). The resulting images are then computationally merged into a 3D reconstruction. As reported by Beeby et al. ${ }^{21}$, using electron cryotomography methodology it is possible to study the organization of peptidoglycan in envelope structure of Gram-negative bacteria. The use of this innovative technology may clarify the mechanisms and targets of aPDT and helps to identify ideal parameters and clinical protocols.

Therefore, the aim of this study is to use Electron cryotomography to identify morphological and structural change in Gram negative bacteria after lethal and sub-lethal dose of antimicrobial photodynamic therapy using methylene blue as a photosensitizer and a low power light emitted diode (LED) (visible red light) and compare these effects with the effects of penicillin.

\section{2 - Materials and Methods}

\section{1 - E. coli strain and culture conditions}

E. coli strains were grown at $30^{\circ} \mathrm{C}$ in $\mathrm{LB}$ broth for $24 \mathrm{hs}$ to reach exponential phase.

A suspensions of $E$. coli were diluted in $3 \mathrm{ml}$ of PBS solution to a cell density of $10^{7}$ per $\mathrm{mL}$, in a glass test tube. A control group was untreated by either aPDT or antibiotics and submitted to electron cryotomography. 
The tested glass tube with E. coli were then incubated with $60 \mathrm{mM}$ of methylene blue (MB) (Sigma Aldrich, Milwaukee, USA) for 5 min in the absence of light. A LED (LumiLEDs, Phillips - Netherlands), with a peak wavelength at $660 \mathrm{~nm}$, corresponding to the region of maximal absorption of MB, was used as the light source (power output of 100 $\mathrm{mW}$ ). The irradiations were performed from the bottom to the top for 30 and 180 seconds, resulting in an energy of 3 and $18 \mathrm{~J}$.

\subsection{2 - Antibiotic therapy}

E. coli were resuspended in PBS solution as reported above and incubated with $0.3 \mu \mathrm{g} / \mathrm{ml}$ penicillin for 1 hour at $30^{\circ} \mathrm{C}$ with shaking.

\section{3 - Electron cryotomography and image analysis}

Immediately before plunge freezing, the sample with the tested cell were mixed with colloidal gold pretreated with BSA to avoid particle aggregation ${ }^{22}$.

$3 \mu 1$ gold-cells mixture were applied to R2/2 copper/rhodium Quantifoil TM grids (Quantifoil Micro Tools), or R2/2 Cflat ${ }^{\mathrm{TM}}$ grids (Protochips). Excess liquid was blotted and the grids were plunge frozen in liquid ethane or ethane propane mixture ${ }^{23}$.

Images were collected using a FEI Polara TM (FEI) $300 \mathrm{kV}$ field emission gun transmission electron microscope equipped with a Gatan energy filter and a lens-coupled 4,000 × 4,000 Ultracam (Gatan) or a direct detector in counting mode using the 'K2 Summit' detector (Gatan). Tilt series from $-65^{\circ}$ to $65^{\circ}$ in 1 degree increments and an underfocus of -8 to $-10 \mu \mathrm{m}$, and effective pixel sizes after $2 \times 2$ binning between 6.4 and $6.6 \AA$ were recorded using Leginon or UCSFtomo. A cumulative dose of $\sim 160$ electrons/ $\AA^{2}$ was used for each tilt series. Tilt series were aligned using the IMOD software package, CTF corrected and SIRT reconstructed using TOMO3D. Subvolume averaging and 3-fold symmetrizing was done using PEET). Visualization and volume measurements were done using Image $\mathbf{J}$ software.

\section{4 - Microbiologic analysis}




\section{2 - Antimicrobial experiments}

\subsection{1 - Photodynamic therapy}

Suspensions of E.coli in stationary phase were diluted in PBS to a cell density of $10^{7}$ per ml, and $200 \mu$ laliquots were added to wells of a 96-well plate followed by removal of $10 \mathrm{ml}$ aliquots for serial dilution and streaking on square BHI agar plates for colony forming units (CFUs) enumeration according to the method of Jett et $\mathrm{al}^{24}$. Bacteria were incubated with $60 \mathrm{mM}$ of MB for 5 minutes followed by illumination with 660-nm LED (LumiLEDs, Phillips Netherlands) for 30 and 180 seconds corresponding to the delivery of 3 and $18 \mathrm{~J}$ of energy. Another bacterial sample was incubated with penicillin $(0.3 \mu \mathrm{g} / \mathrm{ml})$ for 1 hour. Survival fractions were determined from the CFUs in the initial innoculum and compared with the remaining after aPDT or after antibiotic treatment.

\section{5 - Fluorescent analysis}

Following the same procedure an E. coli biofilms were grown in glass-cover slides for $72 \mathrm{~h}$ at $37^{\circ} \mathrm{C}$. After $72 \mathrm{~h}$ biofilm was visualized using the LIVE/DEAD fluorescent microscopy showing a single layer of cells with the clusters covering approximately $70 \%$ of the glass surface. The cover slides were incubated with MB $100 \mu \mathrm{M}$ for 2 minutes and the irradiated as previously described.

Live/Dead BacLight (Bacterial Viability Kit) was then added according to the manufacturer's instructions. The Syto9 stain was used with 480-nm excitation and 500-nm emission, to stain living bacterial cells green. The propidium iodide stain (490-nm excitation and 635-nm emission) was used to stain dead bacterial cells red.

\section{3 - Results}

To investigate the effects of antimicrobial photodynamic therapy in a Gram-negative bacteria, the cells were imaged after challenging with lethal and sublethal dose of aPDT and to compare the damage to cell's envelope, penicillin a beta-lactam antibiotic with known mechanism of action in cell wall, was also used.

The microbiological analysis showed that the mean values of $\mathrm{CFU} / \mathrm{mL}$ of $E$. coli control cells or light treated only, did not present statistically significant reduction $(\mathrm{p}>0.05)$ as well as a $60 \mu \mathrm{M}$ concentration of MB did not show any toxicity to the cells after incubation for 5 minutes in the dark $(\mathrm{p}>0.05)$. After 30 seconds, 180 seconds of irradiation or after 1hour treatment with penicillin, a significant reduction in cell viability was observed. Furthermore, penicillin and aPDT with 180 seconds of light irradiation achieved the highest bacterial reduction. (Figure 1)

Proc. of SPIE Vol. 11070 110708W-5 


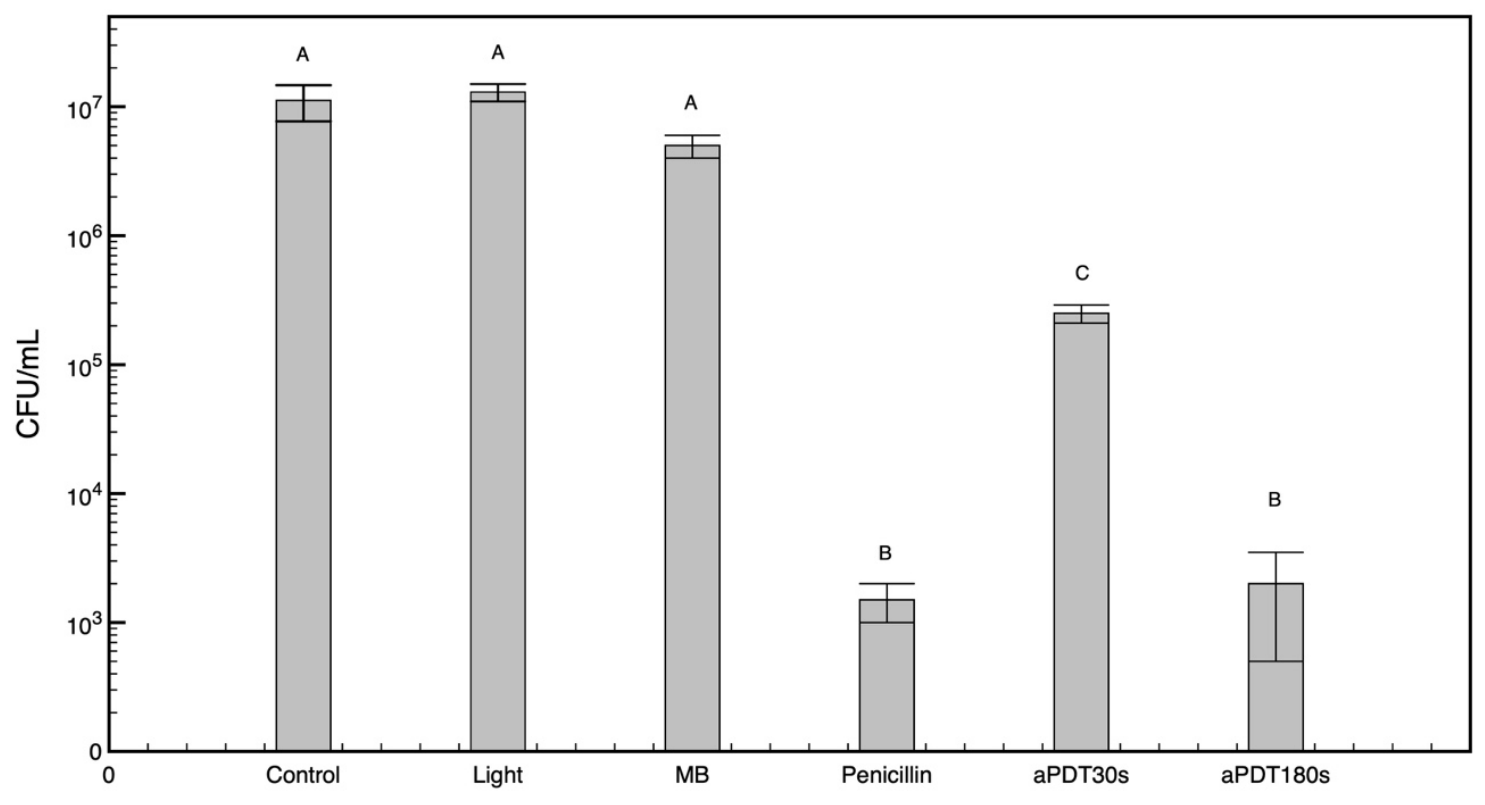

Figure 1: Mean and standard deviation of viable bacteria (CFU) after each treatment. Different letters indicate differences between groups $(\mathrm{p}<0.05)$

Although Gram-positive bacteria present a thick cell wall of peptidoglycan layers that encircle the cytoplasmic membrane, Gram-negative bacteria have an outer phospholipid membrane, a thinner peptidoglycan layer and an inner membrane, forming it cells envelope, as it possible to see on figure 2. 


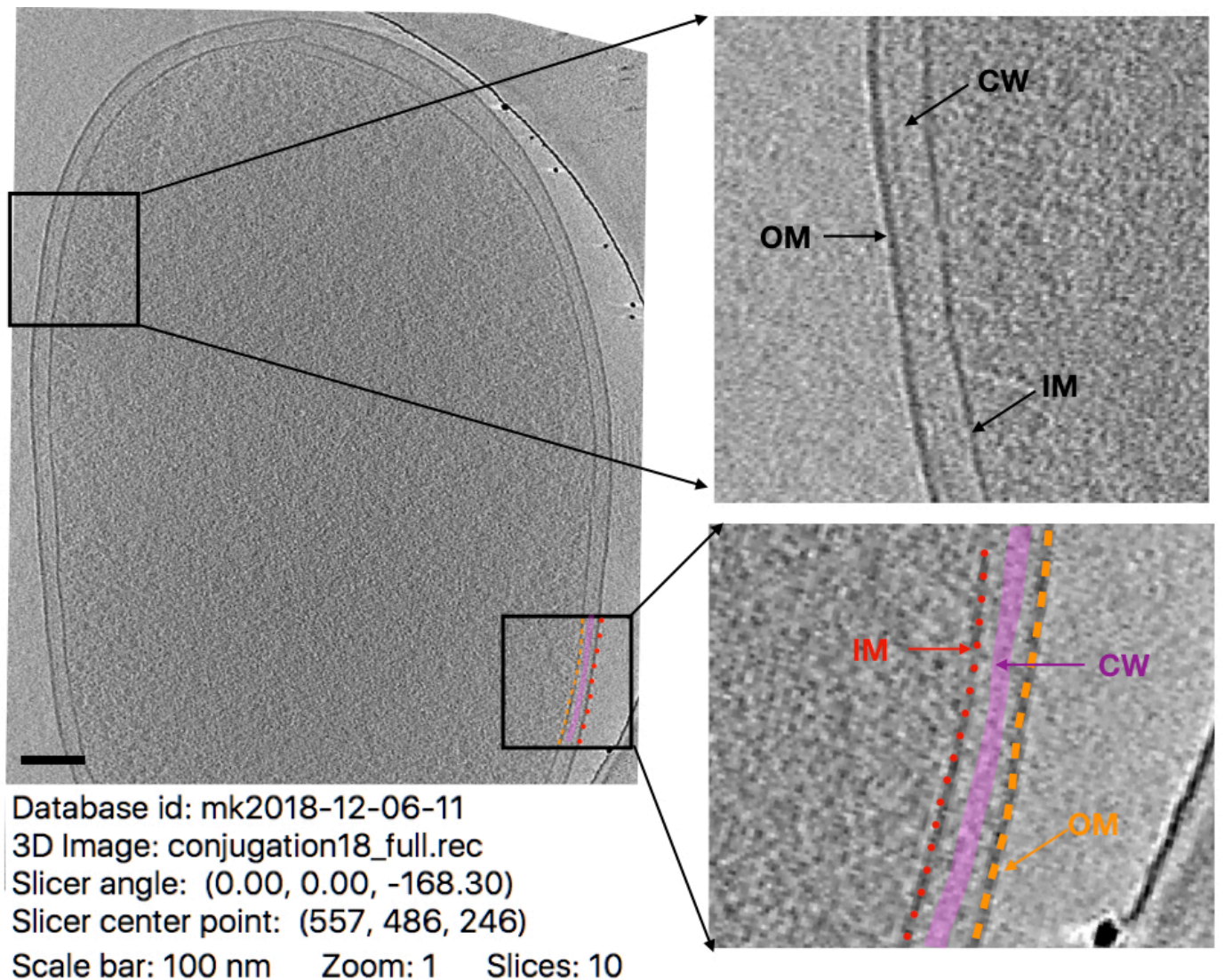

Figure 2: a representative image of $E$. coli without any treatment showing the characteristic envelope structure of a Gramnegative bacteria. OM - outer membrane, $\mathrm{CW}$ - cell wall and IM - inner membrane.

Beta-lactam antibiotic acts by inhibiting the synthesis of the peptidoglycan layer of bacterial cell wall. The peptidoglycan layer is important for cell wall structural integrity, being the primary component of the wall. Penicillin is able to kill bacteria by preventing the cross-linking of peptidoglycan and causing weaken and lyse of cell wall.

Therefore, as expected, when submitted to beta-lactam antibiotic challenge E. coli envelope presents cell wall lost, altered morphology of bacteria envelope, rupture in inner and outer membrane, presence of vesicles and clear sign of cell lysis (figure 2). 


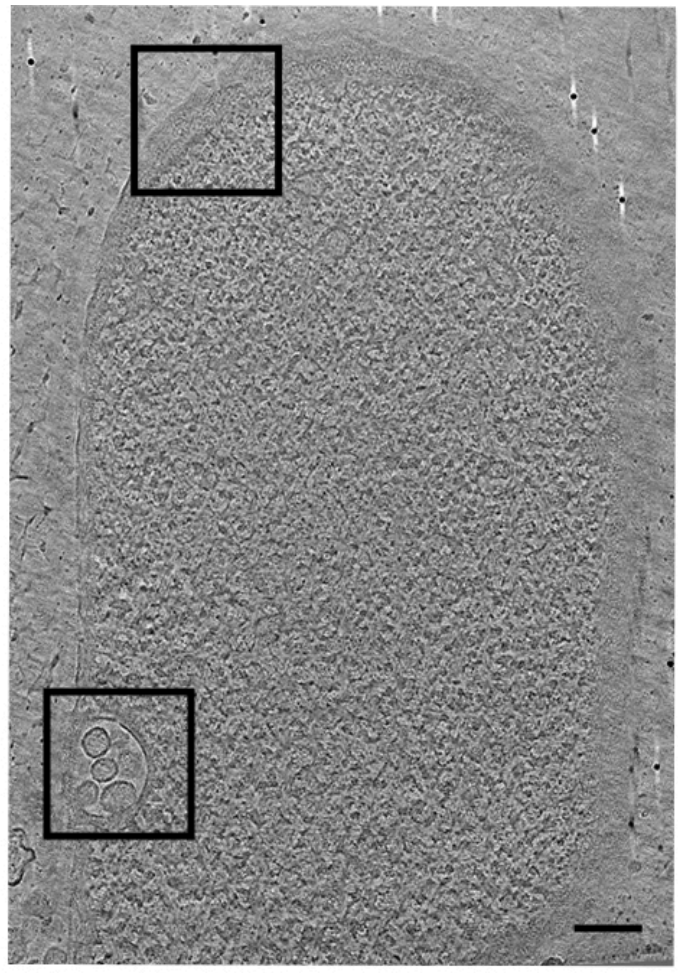

Database id: mk2019-01-13-2

3D Image: Ecoli_Penicillin1_full.rec

Slicer angle: $(0.00,0.00,0.00)$

Slicer center point: $(465,481,255)$

Scale bar: $100 \mathrm{~nm} \quad$ Zoom: $1.5 \quad$ Slices: 10
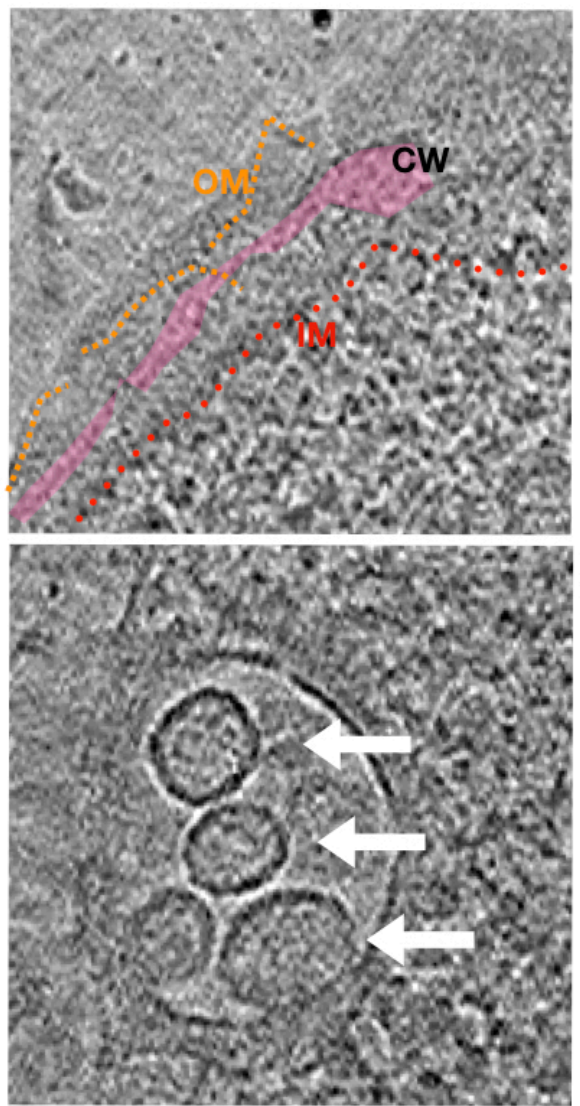

Figure 3: representative tomographic slices of cryosection through E. coli cell treated with penicillin. Cell lysis and evidence of outer membrane, inner membrane and cell wall fragmentation are shown. Arrows point the presence of vesicles.

When treated with sub-lethal dose of aPDT, localized damage to the outer and inner membrane is presented, with more extensive cell wall fragmentation along the cell envelope. Presence of rupture in the outer membrane and invagination or bulges at the inner membrane is evident. Most of the treated cells present vesicles into the cytoplasm and leakage of intracellular content (figure 3). 


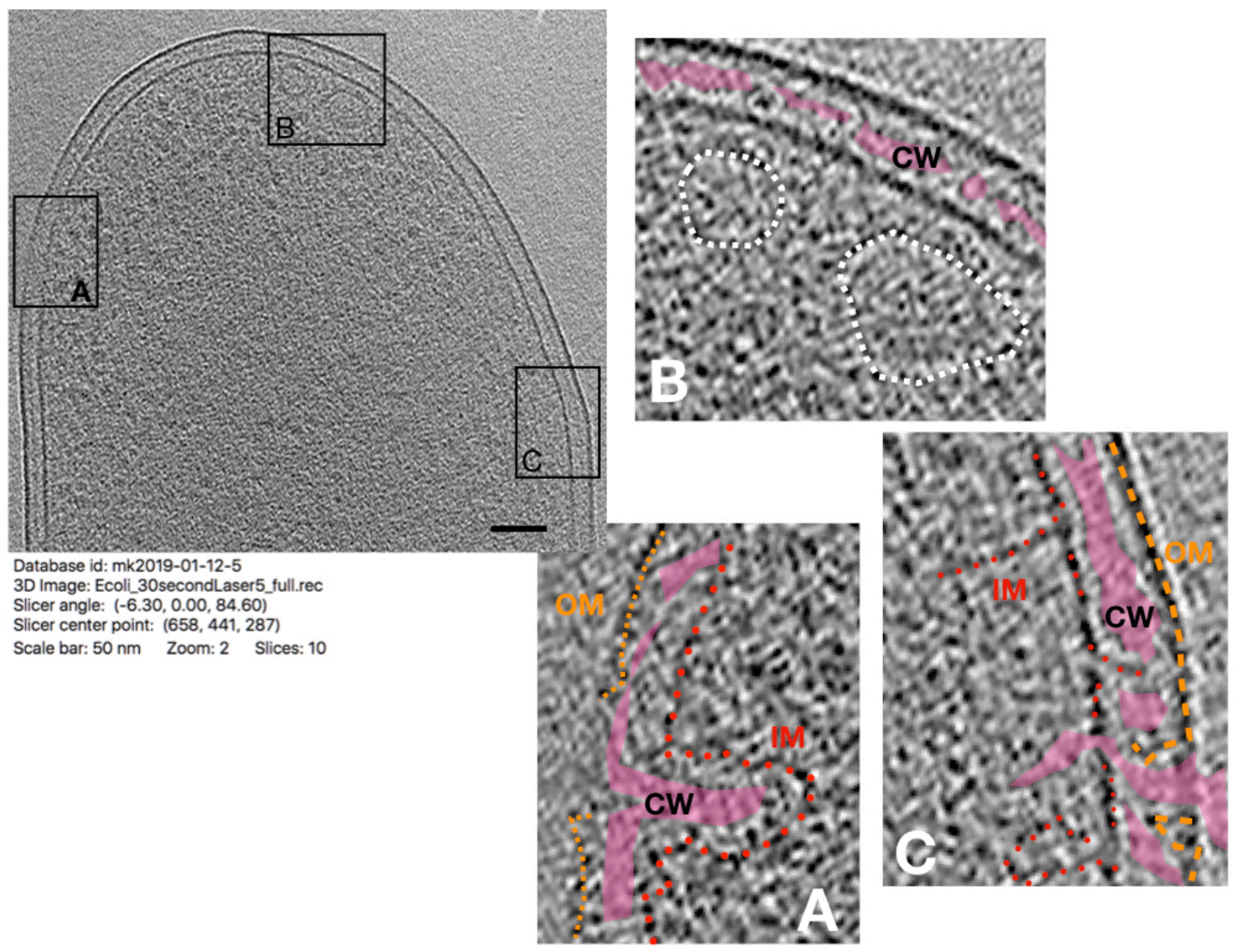

Figure 4: representative tomographic slices of cryosection through $E$. coli cell treated with methylene blue and irradiated with 3J of energy (30 seconds). A) rupture in the outer membrane and invagination or bulges at the inner membrane is evident. B) presence of vesicles into the cytoplasm and C) membrane rupture and cytoplasmic leaking.

Submitted to a lethal dose of Photodynamic therapy (MB plus 18J of irradiation - 180 seconds), the damage to the E.coli cells was more obvious, including rupture of outer and inner membrane, lack of cell wall close to the rupture site and presence of vesicles (Figure 4). 

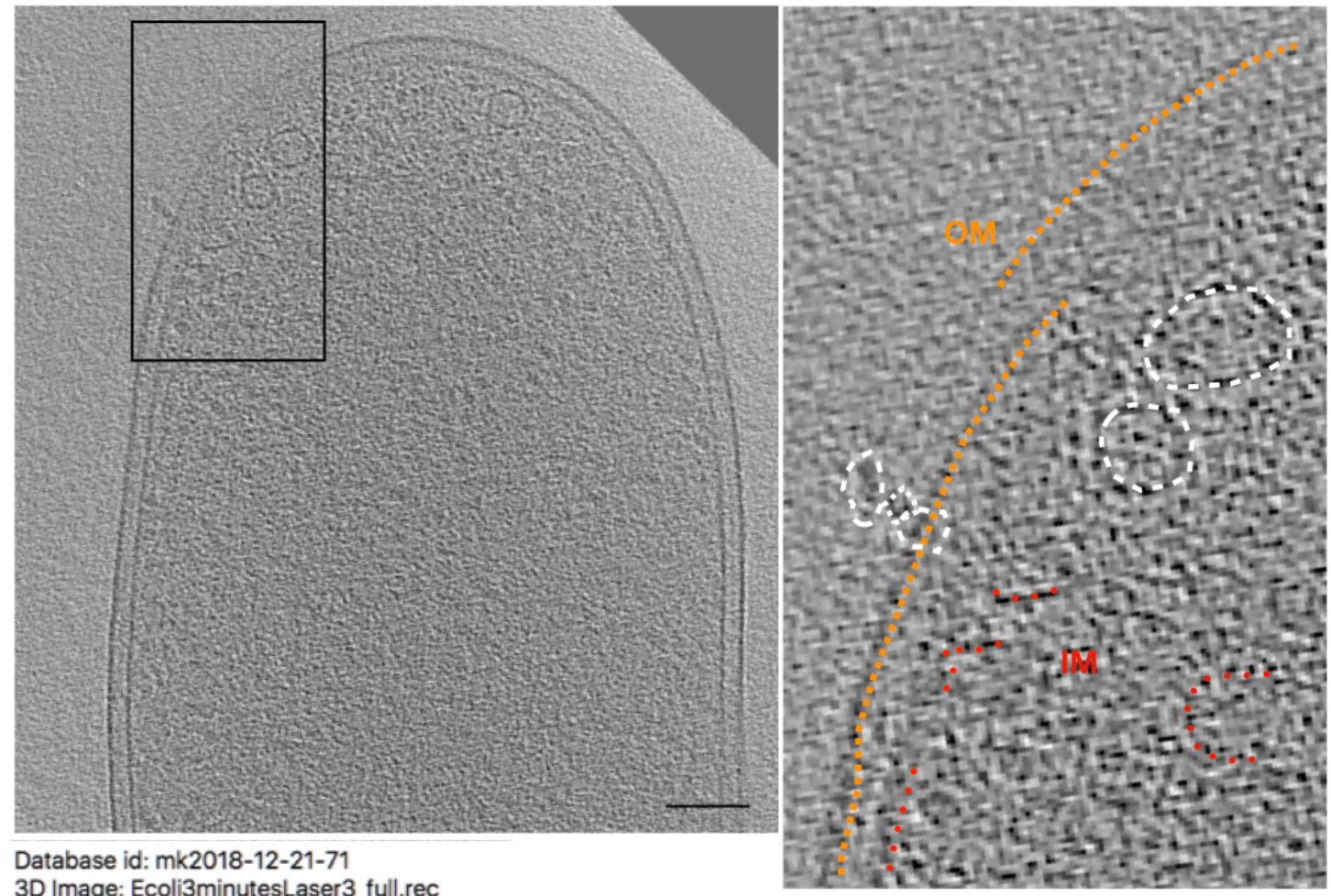

Database id: mk2018-12-21-71

3D Image: Ecoli3minutesLaser3_full.rec

Slicer angle: $(-2.40,0.00,37.90)$

Slicer center point: $(711,558,195)$

Scale bar: $100 \mathrm{~nm} \quad$ Zoom: $1.5 \quad$ Slices: 10

Figure 5: representative tomographic slices of cryosection through E. coli cell treated with methylene blue and irradiated with $18 \mathrm{~J}$ of energy (180 seconds). Note the rupture of outer membrane and leakage of intracellular contents. Cell wall almost disappeared in this section and inner membrane breakup resulting in the vesicles formation.

Fluorescent analysis confirms the membrane damage in the groups treated submitted to lethal and sub-lethal aPDT. Both the aPDT group increase the number of cells marked with propidium iodide (figure 6). Also, these results showed that increasing the energy of irradiation, results in an intensification in cell killing, exhibiting a dose dependence during PDT treatment. 

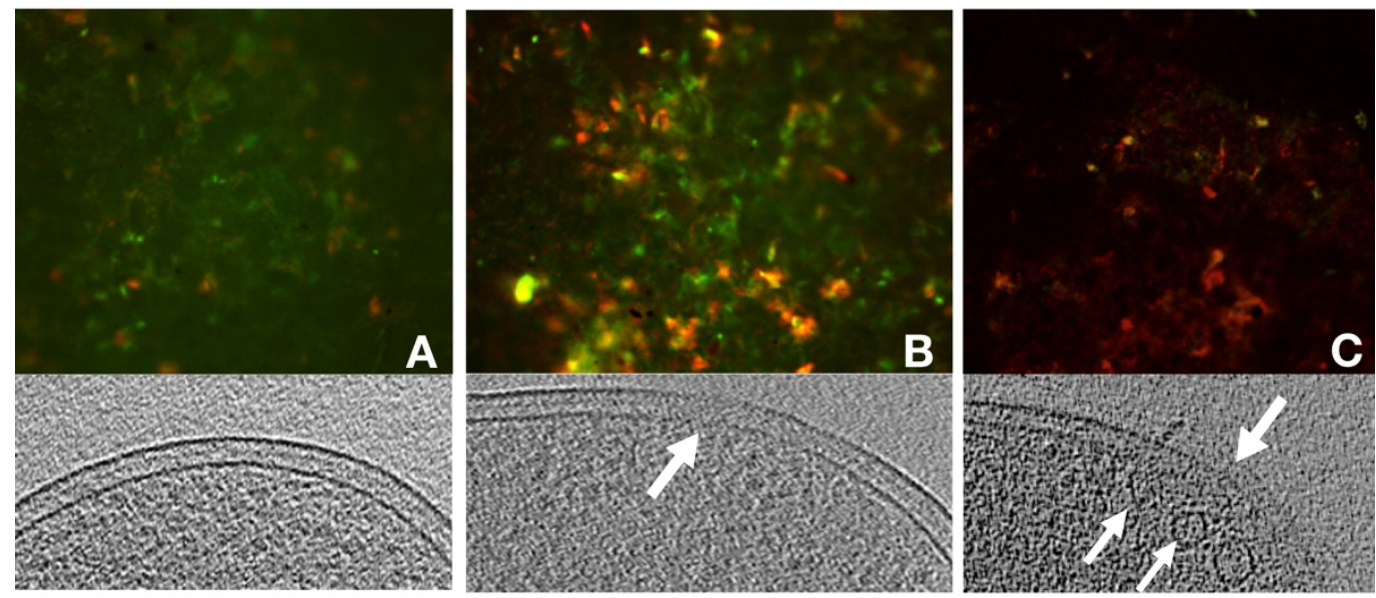

Figure 6: Fluorescence images of biofilm on glass cover slides using live/dead stain and a representative tomographic slice of cryosection. A) Most of the bacteria are viable (green), note the intact envelope; B) Sublethal dose of aPDT some of the bacteria are dead, note the damage at inner and outher membrane (arrow); C) Lethal PDT dose, most of the bacteria are dead (red), at the tomographic slice of cryosection, arrow show a significative damage to cell envelope.

\section{4 - Discussion}

This study evaluated the effects of Methylene blue and light irradiation on Gram negative bacteria $E$. coli and the results are in accordance with a series of previously published papers showing the effect of antimicrobial photodynamic therapy on different microorganisms $\mathrm{s}^{7,25,26,1,14}$.

Two basic mechanisms have been proposed to explain the damage caused to bacteria during PDT, however the exact mechanism by which antimicrobial PDT kills microorganisms, especially Gram-negative bacteria, has not been fully elucidated until now. One of the mechanisms involve DNA damage and the second mechanism damage to the bacteria envelope, allowing leakage of cellular contents or inactivation of membrane transport systems and enzymes ${ }^{27}$. However, even with various authors concluding that DNA damage occurs, it may not be the prime target of antimicrobial PDT. One argument is that Deinococcus radiodurans, which is a bacteria that have a very efficient DNA repair mechanism and one of the most radiation-resistant organisms can easily killed by $\mathrm{PDT}^{28}$. On the other hand, other authors suggests damage at 
membrane level, specially using short pre-irradiation time and lower energy ${ }^{29,7,30}$. The results of this paper, showed throughout electro cryotomography, a more precise tool for small scale cell structure, damage to outer and inner membrane, as well as to cell wall, using 2 minutes of pre-irradiation time and 3 or $18 \mathrm{~J}$ of total irradiation energy. Confirming previous reports $^{31,32}$, also the damage to membrane saw at penicillin treated bacteria is compatible to the finds found in PDT treated bacteria, such as outer and inner membrane rupture and presence of vesicles (Figures 3 and 5).

Different photosensitizers have been used in antimicrobial PDT, such as Toluidine blue ${ }^{33}$, Rose Bengal ${ }^{34}$, Azulene $^{35}$, Erythrosine ${ }^{36}$ and Malachite green ${ }^{37}$. Still, Methylene blue (MB) is one of the most employed photosensitizer for antimicrobial PDT $^{38,39}$. Methylene blue is a cationic phenothiazinium dye in physiologic $\mathrm{pH}$, have high selectivity with minimal damage to host tissue, presents low level of photobleaching, absorption band in biologic window and produce reactive oxygen species at high yelds ${ }^{40}$. Cationic photosensitizers, are also known to be more active than the corresponding anionic or non-ionic compounds against Gram negative bacteria ${ }^{41}$, since the outer membrane of Gram-negative bacteria contents a layer of dense negatively charged lipopolysaccharides and lipoproteins. The highly anionic nature of lipopolysaccharide, i.e, the presence of covalently bound phosphate groups, acidic sugars, and fatty acyl groups, allows it to easily bind to cationic photosensitizers ${ }^{42}$.

Therefore, MB was the chosen PS in this experiment, due to it positive charge may provide a better affinity of the PS to the complex cell envelope and especially its lipopolysaccharide layer.

Since photodynamic therapy has an energy-response behavior ${ }^{43}$, was tested a sub-lethal dose with $3 \mathrm{~J}$ of energy and a high energy of $18 \mathrm{~J}$, this parameters were based on the parameters recommended by Garcez \& Hamblin ${ }^{15}$.

Photosensitizers such as MB are known to promote peroxidation of unsaturated phospholipids. At the molecular level, mechanism of peroxidation leads to an alteration of the structural characteristics of the phospholipids involving breaking of the lipid chain and formation of ketones, aldehydes, and carboxylic acids ${ }^{44}$. Despite studies on the chemistry of phospholipid peroxidation, little is known of the deep repercussions that such molecular modifications have on the membrane cohesion and cell shape ${ }^{45}$.

Damage at the molecular level promoted by $\mathrm{MB}$, is regulated by the localization of the photosensitizer. Photodamage due to electron or hydrogen abstraction (Photodynamic type I reaction) by the photosensitizer, relies on close proximity of the photosensitizer and the biomolecular target. Photodynamic type II processes which produces singlet 
oxygen will also react with molecules involved in the maintenance and structure of the cell wall/membrane such as phospholipids and peptides. The structure of biological membranes is strongly affected by oxidative stress resulting in a variety of the cell responses that are dependent on diverse conditions. Among the diversity of studies, peroxidation of the lipids that compose the membrane has received recognition as one of the key factors that eventually lead to cell death ${ }^{46,44}$.

Lipid peroxidation alter the structural characteristics of the phospholipids that may bring significant alterations on molecular organization, molecular diffusion, and composition of the membrane. Lipid chains may assume new conformations and eventually chain cleavage occurs due to the propagation of the peroxidation reaction ${ }^{44,45}$. The damage to outer and inner membrane revealed in figures 4 and 5, are compatible with these oxidative reactions, especially using lethal dose when it is possible to clear see membranes rupture.

One of the cell wall main function is to provide resistance against the internal/external osmotic pressure and, in most bacteria, it is responsible to cell morphology. Since last century, it has been known that penicillin kills susceptible bacteria by inhibiting the transpeptidase reaction, that cross-link cell wall peptidoglycan, a mesh-like polymer that encompasses the entire cell. It is well known that when a penicillin-susceptible cells grown in the presence of this antibiotic, the integrity of cell wall is lost and the bacteria either ruptures or its membrane is damage beyond repair ${ }^{32,31}$. This exact mechanism is seen on figure 3, when the cell wall is lost, the osmotic pressure break the membranes and kills the bacteria. A similar result was found on bacteria submitted to sub-lethal dose of PDT (Figure 4 B and C), cell wall fragmentation leads to membrane rupture and leakage of cytoplasmic content and consequently cell death.

Numerous reports ${ }^{47,48,49}$ has been using Propidium iodide (PI) to characterize the dead or nonviable cells from living prokaryotic cells, as PI only stain cells with irreparably damaged membranes that can be described as nonviable or dead. The results of this study showed an increase of bacteria stained with PI after 1hour penicillin treatment and also after aPDT. The red fluorescence signal was significantly higher when a $18 \mathrm{~J}$ total energy was applied when compared to $3 \mathrm{~J}$ of total energy (Figure 6).

An expected structure found on penicillin treated group and PDT group is the presence of vesicles. Although interest in membrane vesicles (MV) has increased in recent years, very little is known about the mechanism of MV production and several molecular model for MV production have been proposed. Membrane Vesicles may be formed when the outer membrane expands faster than the underlying peptidoglycan layer ${ }^{50}$. This could causes localized detachment of 
the peptidoglycan from the outer membrane, if an asymmetric local pressure persists, areas of detachment will 'bulge' and be released from the outer membrane, forming the vesicles ${ }^{51}$.

Recently the development of electron cryotomography has allowed the visualization and understanding of complex structure of microorganisms. Also this scientific tool permits to visualization of intact cells and another biological structures close to naïve state in a molecular level ${ }^{52,53}$.

As far as we know this is the first study to use electron cryotomography to study the effects of sub-lethal and lethal dose of antimicrobial photodynamic therapy in cell envelope of a Gram-negative bacteria. The results showed that, in the parameters used in this study, i.e., cationic photosensitizer, shorter pre-irradiation time, low and high irradiation energy, the main damage to cell envelope occurs in outer membrane, followed by cell wall and inner membrane. aPDT promoted membrane rupture, cell wall fragmentation, cytoplasmic leakage and formation of membrane vesicles. These events resulted in energy-dependent bacterial death.

Based on the results, electron cryotomography may contribute to novel insights on mechanisms of antimicrobial photodynamic therapy in the future.

\section{5 - REFERENCES}

1. St. Denis TG, Dai T, Izikson L, et al. All you need is light, antimicrobial photoinactivation as an evolving and emerging discovery strategy against infectious disease. Virulence 2011.

2. Yamada M, Foote M, Prow TW. Therapeutic gold, silver, and platinum nanoparticles. Wiley Interdiscip. Rev. Nanomedicine Nanobiotechnology 2015.

3. Justan I, Cernohorska L, Dvorak Z, Slavicek P. Plasma discharge and time-dependence of its effect to bacteria. Folia Microbiol. (Praha). 2014.

4. Wainwright M. In defence of "dye therapy." Int. J. Antimicrob. Agents 2014.

5. Garcez AS, Nunez SC, Hamblin MR, Ribeiro MS. Antimicrobial Effects of Photodynamic Therapy on Patients with Necrotic Pulps and Periapical Lesion. J. Endod. 2008;34(2).

6. Garcez AS, Arantes-Neto JG, Sellera DP, Fregnani ER. Effects of antimicrobial photodynamic therapy and surgical endodontic treatment on the bacterial load reduction and periapical lesion healing. Three years follow up. Photodiagnosis Photodyn. Ther. 2015;12(4).

7. Garcez AS, Nunez SC, Azambuja N, et al. Effects of photodynamic therapy on gram-positive and gram-negative bacterial biofilms by bioluminescence imaging and scanning electron microscopic analysis. Photomed. Laser Surg. 2013;31(11).

8. Sabino CP, Garcez AS, Nunez SC, Ribeiro MS, Hamblin MR. Real-time evaluation of two light 
delivery systems for photodynamic disinfection of Candida albicans biofilm in curved root canals. Lasers Med. Sci. 2014;30(6).

9. Dai T, Huang YY, Hamblin MR. Photodynamic therapy for localized infections-State of the art. Photodiagnosis Photodyn. Ther. 2009.

10. Allison RR. Photodynamic therapy: Oncologic horizons. Futur. Oncol. 2014.

11. Azaripour A, Dittrich S, Van Noorden CJF, Willershausen B. Efficacy of photodynamic therapy as adjunct treatment of chronic periodontitis: a systematic review and meta-analysis. Lasers Med. Sci. 2018.

12. Ozog DM, Rkein AM, Fabi SG, et al. Photodynamic Therapy: A Clinical Consensus Guide. Dermatologic Surg. 2016.

13. Garcez AS, Nunez SC, Hamblim MR, Suzuki H, Ribeiro MS. Photodynamic therapy associated with conventional endodontic treatment in patients with antibiotic-resistant microflora: A preliminary report. J. Endod. 2010;36(9).

14. Wainwright M, Maisch T, Nonell S, et al. Photoantimicrobials - are we afraid of the light? Lancet Infect. Dis. 2017.

15. Garcez AS, Hamblin MR. Methylene Blue and Hydrogen Peroxide for Photodynamic Inactivation in Root Canal - A New Protocol for Use in Endodontics. Eur. Endod. J. 2017.

16. Misba L, Zaidi S, Khan AU. A comparison of antibacterial and antibiofilm efficacy of phenothiazinium dyes between Gram positive and Gram negative bacterial biofilm. Photodiagnosis Photodyn. Ther. 2017.

17. García I, Ballesta S, Gilaberte Y, Rezusta A, Pascual Á. Antimicrobial photodynamic activity of hypericin against methicillin-susceptible and resistant Staphylococcus aureus biofilms. Future Microbiol. 2015.

18. Hanakova A, Bogdanova K, Tomankova K, et al. The application of antimicrobial photodynamic therapy on S. aureus and E. coli using porphyrin photosensitizers bound to cyclodextrin. Microbiol. Res. 2014.

19. Terra Garcia M, Correia Pereira AH, Figueiredo-Godoi LMA, Jorge AOC, Strixino JF, Junqueira JC. Photodynamic therapy mediated by chlorin-type photosensitizers against Streptococcus mutans biofilms. Photodiagnosis Photodyn. Ther. 2018.

20. Baptista A, Sabino CP, Núñez SC, Miyakawa W, Martin AA, Ribeiro MS. Photodynamic damage predominates on different targets depending on cell growth phase of Candida albicans. J. Photochem. Photobiol. B Biol. 2017.

21. Beeby M, Gumbart JC, Roux B, Jensen GJ. Architecture and assembly of the Gram-positive cell wall. Mol. Microbiol. 2013.

22. Iancu C V., Tivol WF, Schooler JB, et al. Electron cryotomography sample preparation using the Vitrobot. Nat. Protoc. 2007.

23. Tivol WF, Briegel A, Jensen GJ. An improved cryogen for plunge freezing. Microsc. Microanal. 2008.

24. Jett BD, Hatter KL, Huycke MM, Gilmore MS. Simplified agar plate method for quantifying viable bacteria. Biotechniques 1997;23(4):648-50.

25. Usacheva MN, Teichert MC, Sievert CE, Biel MA. Effect of Ca2+ on the photobactericidal efficacy of methylene blue and toluidine blue against gram-negative bacteria and the dye affinity for lipopolysaccharides. Lasers Surg. Med. 2006.

26. Usacheva MN, Teichert MC, Biel MA. Comparison of the methylene blue and toluidine blue photobactericidal efficacy against gram-positive and gram-negative microorganisms. Lasers Surg. 
Med. 2001.

27. Hamblin MR, Hasan T. Photodynamic therapy: A new antimicrobial approach to infectious disease? Photochem. Photobiol. Sci. 2004.

28. Schäfer M, Schmitz C, Horneck G. High sensitivity of Deinococcus radiodurans to photodynamically-produced singlet oxygen. Int. J. Radiat. Biol. 1998.

29. Bertoloni G, Rossi F, Valduga G, Jori G, Ali H, van Lier JE. Photosensitizing activity of waterand lipid-soluble phthalocyanines on prokaryotic and eukaryotic microbial cells. Microbios 1992.

30. Dosselli R, Millioni R, Puricelli L, et al. Molecular targets of antimicrobial photodynamic therapy identified by a proteomic approach. J. Proteomics 2012.

31. Wise EM, Park JT. Penicillin: its basic site of action as an inhibitor of a peptide cross-linking reaction in cell wall mucopeptide synthesis. Proc. Natl. Acad. Sci. U. S. A. 1965.

32. Yocum RR, Waxman DJ, Rasmussen JR, Strominger JL. Mechanism of penicillin action: penicillin and substrate bind covalently to the same active site serine in two bacterial D-alanine carboxypeptidases. Proc. Natl. Acad. Sci. 2006.

33. Goh EX, Tan KS, Chan YH, Lim LP. Effects of root debridement and adjunctive photodynamic therapy in residual pockets of patients on supportive periodontal therapy: A randomized split-mouth trial. Photodiagnosis Photodyn. Ther. 2017.

34. Chui C, Aoki A, Takeuchi Y, et al. Antimicrobial effect of photodynamic therapy using highpower blue light-emitting diode and red-dye agent on Porphyromonas gingivalis. J. Periodontal Res. 2013.

35. Silva Garcez A, Nunez SC, Lage-Marques JL, Jorge AOC, Ribeiro MS. Efficiency of NaOCl and laser-assisted photosensitization on the reduction of Enterococcus faecalis in vitro. Oral Surgery, Oral Med. Oral Pathol. Oral Radiol. Endodontology 2006;102(4):93-8.

36. Rolim JPML, De-Melo MAS, Guedes SF, et al. The antimicrobial activity of photodynamic therapy against Streptococcus mutans using different photosensitizers. J. Photochem. Photobiol. B Biol. 2012.

37. Prates RA, Yamada AM, Suzuki LC, et al. Bactericidal effect of malachite green and red laser on Actinobacillus actinomycetemcomitans. J. Photochem. Photobiol. B Biol. 2007.

38. Wainwright M, Byrne MN, Gattrell MA. Phenothiazinium-based photobactericidal materials. $J$. Photochem. Photobiol. B Biol. 2006.

39. Wainwright M, Antczak J, Baca M, Loughran C, Meegan K. Phenothiazinium photoantimicrobials with basic side chains. J. Photochem. Photobiol. B Biol. 2015.

40. Ileri Ercan N, Stroeve P, Tringe JW, Faller R. Molecular Dynamics Modeling of Methylene BlueDOPC Lipid Bilayer Interactions. Langmuir 2018.

41. Banfi S, Caruso E, Buccafurni L, et al. Antibacterial activity of tetraaryl-porphyrin photosensitizers: An in vitro study on Gram negative and Gram positive bacteria. J. Photochem. Photobiol. B Biol. 2006.

42. Usacheva MN, Teichert MC, Biel MA. The Interaction of Lipopolysaccharides with Phenothiazine Dyes. Lasers Surg. Med. 2003.

43. Garcez AS, Ribeiro MS, Tegos GP, Núñez SC, Jorge AOC, Hamblin MR. Antimicrobial photodynamic therapy combined with conventional endodontic treatment to eliminate root canal biofilm infection. Lasers Surg. Med. 2007;39(1):59-66.

44. Mertins O, Bacellar IOL, Thalmann F, Marques CM, Baptista MS, Itri R. Physical damage on giant vesicles membrane as a result of methylene blue photoirradiation. Biophys. J. 2014.

45. Caetano W, Haddad PS, Itri R, et al. Photo-induced destruction of giant vesicles in methylene blue 
solutions. Langmuir 2007.

46. Bochkov VN, Oskolkova O V, Birukov KG, Levonen A-L, Binder CJ, Stoeck1 J. Generation and Biological Activities of Oxidized Phospholipids. Antioxid. Redox Signal. 2010.

47. Yang Y, Xiang Y, Xu M. From red to green: The propidium iodide-permeable membrane of Shewanella decolorationis S12 is repairable. Sci. Rep. 2015.

48. Sträuber H, Müller S. Viability states of bacteria-Specific mechanisms of selected probes. Cytom. Part A 2010.

49. Davey HM. Life, Death, and In-Between: Meanings and Methods in Microbiology. Appl. Environ. Microbiol. 2011.

50. WENSINK J, WITHOLT B. Outer-Membrane Vesicles Released by Normally Growing Escherichia coli Contain Very Little Lipoprotein. Eur. J. Biochem. 1981.

51. Mashburn-Warren LM, Whiteley M. Special delivery: Vesicle trafficking in prokaryotes. Mol. Microbiol. 2006.

52. Hagen WJH, Wan W, Briggs JAG. Implementation of a cryo-electron tomography tilt-scheme optimized for high resolution subtomogram averaging. J. Struct. Biol. 2017.

53. Chreifi G, Chen S, Metskas LA, Kaplan M, Jensen GJ. Rapid tilt-series acquisition for electron cryotomography. J. Struct. Biol. 2019;205(2):163-9. 